\title{
Perspectivas para segurança alimentar e nutricional no Brasil
}

\section{Prospects for food and nutricional safety in Brazil}

Walter Belik

Professor Livre Docente do Instituto de Economia e Coordenador do Núcleo de Economia Agrícola da Unicamp - Universidade Estadual de Campinas, SP

E-mail: belikळeco.unicamp.br

\section{Resumo}

O presente texto faz uma avaliação do conceito de segurança alimentar demonstrando como a sua definição estabelece limites e prioridades para as políticas sociais. Considerando que é dever do Estado garantir o acesso de todos os cidadãos aos alimentos quantidade suficiente, com qualidade e regularidade, o artigo apresenta os contornos do Programa Fome Zero adotado pelo governo brasileiro em 2003. Nesse sentido, há um detalhamento da metodologia utilizada para definir as populações de risco e, a partir de então, uma descrição sumária de cada uma das ações que estão sendo empreendidas atualmente pelo programa. Finalmente são apresentadas conclusões sobre o assunto

Palavras Chaves: Segurança Alimentar, Fome, Política Social, Pobreza

\section{Abstract}

This paper makes an assessment on the concept of Food Safety demonstrating how its definition establishes limits and priorities for the social policies. Considering that it is the duty of the state to guarantee the access of all the citizens to enough quality food on a regular basic this article presents the design of the Zero Hunger Program adopted by the Brazilian government in 2003. Regarding this objective this paper detail the metodology used to evaluate the Brazilian population at risk and depicts each action that is being currently undertaken by the program. Finally, conclusions on the subject are presented

Keywords: Food Security, Food Safety, Hunger, Poverty, Social Policy 


\section{Introdução}

A utilização do conceito de segurança alimentar dá origem a diferentes interpretações. Países ricos, grandes produtores agrícolas, costumam alegar motivos de segurança alimentar para impor barreiras às importações e elevar artificialmente os preços dos alimentos. Países pobres, governados por líderes populistas, utilizam-se desse conceito para tabelar preços e impor pesadas perdas aos produtores agrícolas com o fim de contentar os seus eleitores. Da mesma maneira, a segurança alimentar é invocada por interesses particulares para promover a destruição do meio ambiente ou mesmo a destruição dos hábitos culturais de um povo. Enfim, não há como ignorar a importância das políticas de segurança alimentar como mobilizadoras das forças produtivas.

No Brasil, desde os tempos coloniais, havia uma preocupação por parte dos governantes com a alimentação da população. Essa preocupação termina por se transformar em políticas públicas a partir do século XX, com a emergência dos movimentos sociais contra a carestia. As políticas implementadas desde o início do século passado abrangiam diversos ítens como a política agrícola, os sistemas de abastecimento, controle de preços, distribuição de alimentos etc. Em 1996, porém, essas intervenções pontuais do lado da produção e consumo assumem outra dimensão e têm outros objetivos. Naquele ano o governo brasileiro, juntamente com outra centena de países, passa a olhar esse conjunto de políticas dentro de um esforço geral para a redução da situação de fome em seus territórios. Reunidos na Cúpula Mundial da Alimentação, em Roma, diversos dirigentes de países - entre eles o Brasil - firmaram um compromisso de reduzir pela metade o número de pessoas famintas até 2015.

Anos antes, em 1993, na Conferência Mundial sobre Direitos Humanos, de Viena, o direito à alimentação passou a ser equiparado aos demais direitos do homem estabelecidos na Carta dos Direitos Humanos de $1948^{1}$. Essa mudança fundamental na forma de encarar o direito à alimentação e o compromisso internacional de redução das estatísticas relacionadas com a fome colocam o Estado na posição de provedor e responsável pelo bem estar alimentar de sua população.
Baseado no princípio do direito à alimentação, os governos poderiam receber censuras em nível internacional por não garantir o acesso dos seus cidadãos à alimentação. Para exemplificar essa mudança de enfoque, que ocorreu ao final dos anos go, e que pode ser observada internacionalmente, basta mencionar que, em março de 2002, a Comissão de Direitos Humanos da ONU sobre o Direito à Alimentação enviou um comissário ao Brasil para uma inspeção. O seu relatório, apresentado na $59^{\text {a }}$ reunião da Comissão (em março de 2003) destaca que:

“....Um terço dos brasileiros sofrem de má nutrição e 18 milhões de pessoas sofrem de desnutrição crônica e aguda...” (§ 11, pag. 5)

E mais adiante: “Apesar da fome no Brasil não ser imediatamente óbvia, tendo em vista que as pessoas não morrem de inanição, milhões de pessoas sofrem de má nutrição ou subnutrição. A FAO explica que a presença de fome não está sempre aparente porque o corpo compensa a dieta inadequada com um a redução na atividade física, e no caso das crianças, no seu crescimento...” (§ 12, pag. 5).

A situação crítica relativa à fome gerou o apoio popular e uma enorme adesão das empresas e organizações não governamentais ao Programa Fome Zero (PFZ), lançado por ocasião da eleição do Presidente Lula, em 2003. Em que pese todos os problemas de gestão da administração pública e de articulação entre instâncias de governo, o PFZ representou um avanço em relação às ações isoladas de combate à fome que se encontravam dispersas e sem qualquer tipo de avaliação.

0 presente artigo pretende fazer uma apresentação sumária dos principais elementos do PFZ, adotado pelo governo federal recentemente, seus pressupostos e princípios. Para tanto vamos tomar apenas algum espaço para discutir o conceito de segurança alimentar e a sua influência na determinação do público beneficiário a ser atendido pelo programa. Pretendemos mostrar também como as ações previstas pelo PFZ se apresentam respeitando as características do meio geográfico e social em que se inserem. Finalmente, fazemos algumas considerações finais sobre o alcance imediato e de longo prazo do programa.

\footnotetext{
1 No Brasil existe uma Proposta de Emenda Constitucional de 2001 que altera o artigo $6^{\circ}$. da nossa constituição incluindo o direito à alimentação entre os direitos fundamentais do homem. Atualmente, a constituição brasileira se refere ao direito à vida deixando apenas implícita a questão do direito à alimentação.
} 


\section{Fome e Segurança Alimentar}

O conceito de Segurança Alimentar veio à luz a partir da $2^{a}$ Grande Guerra com mais de metade da Europa devastada e sem condições de produzir o seu próprio alimento. Esse conceito leva em conta três aspectos principais: quantidade, qualidade e regularidade no acesso aos alimentos.

Note-se que está se utilizando a idéia de acesso aos alimentos, o que é muito distinto de disponibilidade de alimentos. Os alimentos podem estar disponíveis, conforme pode ser registrado pelas estatísticas que a FAO levanta para o mundo de tempos em tempos, mas as populações pobres podem não ter acesso a eles, seja por problemas de renda, ou seja devido a outros fatores como conflitos internos, ação de monopólios ou mesmo desvios.

Outro aspecto importante diz respeito à qualidade dos alimentos consumidos. A alimentação disponível para o consumo da população não pode estar submetida a qualquer tipo de risco por contaminação, problemas de apodrecimento ou outros decorrentes de prazos de validade vencidos. Evidentemente, a qualidade dos alimentos diz respeito também à possibilidade de consumi-los de forma digna. Dignidade significa permitir que as pessoas possam comer em um ambiente limpo, com talheres e seguindo as normas tradicionais de higiene. Nesse caso, seriam condenadas certas práticas como ministrar rações, preparados energéticos e outras misturas visando combater os efeitos da desnutrição. Há também uma corrente muito forte de estudiosos e mesmo entre os militantes das causas ambientais que consideram que no aspecto da qualidade para a segurança alimentar não seria admissível o uso dos alimentos transgênicos.

0 último elemento referente à definição de segurança alimentar diz respeito à regularidade. Isso quer dizer que as pessoas têm que ter acesso constante à alimentação (alimentando-se ao menos três vezes ao dia, como se passou a considerar recentemente). Portanto não se considera isenta de risco uma população que tenha acesso restrito aos alimentos como por exemplo aqueles que recebem esporadicamente cestas básicas (Pessanha, 2001).

Mais recentemente, atendendo um pedido dos estados membros participantes da Cúpula Mundial de Alimentação, de 1996, o Comitê de Direitos Econômi- cos, Sociais e Culturais das Nações Unidas emitiu o seu "Comentário Geral 12 - O Direito à Alimentação Adequada”. Esse documento transformou-se em um marco para as organizações de direitos humanos e um norte para toda a comunidade internacional. 0 comentário 12 insiste na necessidade e na obrigação que todos os Estados têm em "respeitar, proteger e realizar o direito". o documento coloca expressamente em seu parágrafo 15 “...sempre que um indivíduo ou grupo é incapaz, por razões além de seu controle, de usufruir do direito à alimentação adequada com recursos à sua disposição, os Estados teriam a obrigação de realizar (prover) o direito diretamente. Esta obrigação também deve existir no caso de vítimas de desastres naturais ou provocados por causas diversas".

Portanto, o direito de se alimentar regularmente e adequadamente não deve ser produto da benemerência ou resultado de ações de caridade mas sim, prioritariamente, de uma obrigação que é exercida pelo Estado que, em última análise, é a representação da nossa sociedade. Vale lembrar também que o conceito de segurança alimentar continua em aberto e também está em discussão. Mais recentemente, já se fala também em soberania e sustentabilidade alimentar.

O emprego da noção de soberania alimentar começa a surgir com força no debate do tema da segurança alimentar, no próprio ano de 1996. Durante a Cúpula Mundial da Alimentação, no foro paralelo da sociedade civil, também realizado em Roma, a reivindicação da soberania alimentar aparece com grande destaque. Esse conceito procura dar importância à autonomia alimentar dos países e está associado à geração de emprego dentro do país e à menor dependência das importações e flutuações de preços do mercado internacional (Maluf, 2000: 59). A soberania alimentar atribui uma grande importância a preservação da cultura e aos hábitos alimentares de um país. Essa posição em torno da soberania alimentar tem encontrado defensores entre os representantes de povos indígenas muito fortes na América Andina, na América Central e entre os pequenos produtores europeus.

A sustentabilidade, por sua vez, incorpora conceitos ligados a preservação do meio ambiente, não utilização de agrotóxicos e da produção extensiva em monoculturas. Os defensores da sustentabilidade, por exemplo, colocam-se frontalmente contra o uso de alimentos transgênicos. 
O que entendemos como fome pode ter muitos significados, mas guarda uma certa distinção em relação aos conceitos anteriores. Tecnicamente a DES Desnutrição Enérgico Proteica é um estado de saúde causado pela falta concomitante de calorias e proteínas e que aparece normalmente associada à infecção ${ }^{2}$. A prevalência de desnutrição pode ser avaliada através de critérios antropométricos (peso/idade; peso/ estatura e estatura/idade). Todavia, um outro tipo de desnutrição denominada enérgico proteica não pode ser avaliado a partir desses métodos e decorre de outros fatores como por exemplo: carência de ferro (anemia ferropriva), carência de iodo (bócio endêmico) e a carência de vitamina A (hipovitaminose A). Todos esses problemas de nutrição caracterizam aquilo que se denomina "fome oculta" 3 .

De outro lado temos também o problema da obesidade que tem uma enorme relevância quando se analisa o quadro da nutrição no Brasil. Segundo pesquisa recente realizada a partir dos dados do SUS - Sistema Único de Saúde no Brasil, o país tem um contingente de 70 milhões de pessoas acima do peso, sendo que desse total, 5 milhões sofrem de obesidade mórbida. Esse número obtido com os dados de 2001 representa o triplo de 20 anos atrás. Os obesos representam um problema de saúde pois, assim como os desnutridos, necessitam de cuidados médicos e, segundo os dados recolhidos junto ao SUS, esse contingente consome $77 \%$ a mais de medicamentos que a população em geral ${ }^{4}$.

Os três conceitos principais tratados até o momento (pobreza, fome e desnutrição) têm uma forte relação entre si, mas não têm o mesmo significado. Segundo Monteiro (1995), a falta de renda torna difícil o acesso às necessidades básicas, como alimentação, vestuário, habitação, educação, cuidados com a saúde etc. Qual a prioridade que a família vai dar para alocar os escassos recursos (por exemplo: moradia x alimentação, ou cuidados com a saúde)? Essa é diferente de família para família. A fome ocorre quando a alimentação diária não supre a energia requerida para manutenção do organismo e para exercício das atividades normais do ser humano. A desnutrição decorre da manifestação de sinais clínicos que provêm da inadequação quantitativa (energia) ou qualitativa (nutrientes) da dieta ou também de doenças que provocam o mau aproveitamento biológico dos alimentos ingeridos.

Assim, é possível que a sociedade seja muito pobre, afetando o acesso a determinadas necessidades (como educação, saúde, moradia), mas não passe fome. Também é possível que pessoas tenham renda suficiente para se alimentar, viver dignamente mas tenham uma alimentação inadequada. Com relação à fome e à desnutrição, Monteiro (1995) afirma que toda fome leva necessariamente à desnutrição, mas nem toda desnutrição se origina da deficiência energética , principalmente na população infantil. Vários fatores, como a deficiência específica de macro e micronutrientes, o desmame precoce, a higiene alimentar precária e a ocorrência excessiva de infecções podem causar a desnutrição infantil, sendo que, por conta disso, considera-se que a desnutrição está mais associada à pobreza do que à fome, devido à carências globais a que a criança está submetida: não apenas a falta de ingestão de alimentos, mas também a diversificação e a adequação nutricional da dieta, conhecimentos básicos de higiene, condição salubres de moradia, cuidados de saúde etc.

No caso brasileiro, não há dúvida que a grande causa da falta de acesso aos alimentos, bem como da desnutrição infantil, é o baixo nível de renda. A Pesquisa Nacional de Saúde e Nutrição - PNSN de 1989 constatou que, ligeiros acréscimos na renda domiciliar traduzem-se em melhor desempenho no crescimento da população até 25 anos de idade. Hoffmann (1995) também constatou correlação negativa entre prevalência de retardo no crescimento na infância e o rendimento mediano das famílias destas crianças.

No entanto, isto não significa que os dois conceitos - fome e pobreza - possam ser tratados como sinônimos. Infelizmente, na ausência de dados diretos, tem-se que considerar as pessoas que não têm renda suficiente para adquirir uma cesta básica como aquelas que "passam fome", ou pelo menos como vulneráveis a isso. 0 principal problema não está nesse ponto, pois é válido que considerem pessoas com renda muito baixas como aquelas vulneráveis à situação de fo-

2 Informação obtida junto à Profa. Maria Cristina Faber Boog da Faculdade de Ciências Médicas da Unicamp

3 Segundo a Profa. Maria Cristina Faber Boog da Faculdade de Ciências Médicas da Unicamp.

4 Dados recolhidos por uma pesquisa conduzida na UFRJ pelos Professores Rosely Schieri e Cid Manso de Melo Viana apresentados no Fórum do Peso Saudável (jornal O Estado de S. Paulo, 10/04/2003) 
me, ou consumo alimentar quantitativamente e qualitativamente inadequados. 0 maior problema está na inadequação dos dados estatísticos para esta aferição e no seu grau de generalização. Os dados de renda predominantemente utilizados pelos estudos do método indireto baseiam-se na PNAD (Pesquisa Nacional de Amostra de Domicílios), que é uma excelente fonte de dados para diversas pesquisas.

Para a definição da população que "passa fome”, as PNADs apresentam as seguintes limitações:

a) só trabalham com dados de renda, e não de consumo. Não se têm dados precisos de onde é gasta a renda das famílias. Esta lacuna é suprida apenas pela POF (Pesquisa de Orçamento Familiar), que é feita apenas a cada 10 anos e só nas regiões metropolitanas;

b) só abrangem as famílias com domicílios temporários ou permanentes. Ou seja, não entra na pesquisa a parcela da população mais vulnerável e desprovida de condições, que é aquela sem moradia, para a qual não se dispõe de nenhuma estimativa para o país; exclui a população rural da região Norte, (exceto Tocantins) uma das áreas mais pobres o país;

c) não incluem recebimento de rendas ou bens de consumo provenientes de doações ou programas governamentais, nem o auto-consumo das famílias agrícolas, o que pode ter um impacto elevado no consumo alimentar.

Ademais, existe uma tendência entre os pobres no sentido de superestimarem e dos ricos subestimarem fortemente sua renda na declaração, fazendo com que as estimativas da pobreza fiquem também subestimadas.

São essas as razões, a nosso ver, que explicam a grande discrepância das pessoas vulneráveis à fome quando se compara a população avaliada segundo as duas metodologias (direta e indireta). Infelizmente, a única fonte de dados que permite fazer este cruzamento é o ENDEF, de 1974/75. Lustosa e Figueiredo (1990) fizeram esta comparação combinando as pessoas com TAE (Taxa de Adequação Energética) menor que 100\% e pessoas com despesa global abaixo de um determinado valor. Segundo os autores, “as disparidades observadas parecem indicar que, neste conjunto de observações, a inadequação alimentar dá-se, em larga medida, independentemente do nível de despesas familiar"(p. 369).

Esta conclusão é ainda bastante válida para os dias atuais, quando a maioria dos estudos para cálculo de indigência utilizam da renda necessária para adquirir uma cesta básica. No entanto, todas estas pesquisas são importantes para um acompanhamento do problema. Mantendo-se a metodologia constante ao longo dos anos, é possível verificar a evolução do problema, mas o seu estado atual é variável, de acordo com a metodologia utilizada.

Diante das dificuldades verificadas na mensuração da indigência/pobreza, é preciso deixar claro que não se pretende, nesse momento, estimar as pessoas que passam fome no país, embora esta seja uma tarefa fundamental para avaliação dos resultados das políticas propostas. Esta é uma tarefa que exige pesquisas amplas que ainda estão em elaboração no país. 0 objetivo mais modesto é o de estimar aquela parcela da população que não possui renda suficiente para garantir sua segurança alimentar estando, portanto, vulnerável à fome.

\section{Estimativas da População Vulnerável à Fome}

A estimativa de público beneficiário utilizada no PFZ tomou como base dois elementos importantes do ponto de vista da renda das famílias. De uma lado, trabalhou-se o dado de renda em termos de poder de compra, levando-se em conta os seus valores em termos regionais, da localização dessas famílias e de possíveis rendas não monetárias que poderiam influenciar no seu poder de compra ${ }^{5}$. De outro lado, analisou-se o poder de compra em si com informações sobre o consumo de cestas básicas regionais e de deflatores de preços diferenciados para entender a evolução do preço dessas cestas ao longo do tempo.

A tabela 1, apresentada a seguir, descreve os resultados das estimativas feitas pelo Projeto Fome Zero, em 2001, com base nas PNADs de 1999 e depois corrigidas em 2003, com base nas PNADs de 2001.

5 Como por exemplo a produção agrícola para o auto-consumo ou mesmo o "não gasto" da renda com o pagamento de aluguéis. 
Tabela ı: Estimativa de Beneficiários de Programas de Combate à Fome 200 I

\begin{tabular}{|l|c|c|c|c|c|}
\hline Regiões & $\begin{array}{l}\text { No. pessoas } \\
\text { pobres (milhões) }\end{array}$ & $\begin{array}{l}\text { No. famílias } \\
\text { pobres (milhões) }\end{array}$ & $\begin{array}{l}\text { \% pessoas } \\
\text { pobres }\end{array}$ & $\begin{array}{l}\text { \% de famílias } \\
\text { pobres }\end{array}$ & $\begin{array}{l}\text { Renda média mensal per } \\
\text { capita disponível (R\$) }\end{array}$ \\
\hline Brasil & 46,126 & 9,998 & 27,3 & 21,4 & 43,09 \\
\hline Áreas metropolitanas & 10,418 & 2,429 & 19,5 & 15,8 & 44,61 \\
\hline Áreas urbanas não metropolitanas & 23,574 & 5,148 & 26,3 & 20,8 & 44,45 \\
\hline Áreas rurais & 12,134 & 2,421 & 47,3 & 37,3 & 39,11
\end{tabular}

Fonte: Projeto Fome Zero.

a: exclusive pensionistas, empregadas domésticas e seus parentes.

Pobres: renda familiar per capita menor que R\$ 71,53 por mês para o NE rural.

Como se observa, a estimativa de beneficiários dos programas de combate à fome alça a 46 milhões de indivíduos ou quase 10 milhões de famílias representando $27,3 \%$ das pessoas e $21,4 \%$ das famílias brasileiras. Observa-se também, que há uma grande concentração dessas famílias nas áreas urbanas não metropolitanas (pequenas e médias cidades) somando 51,1\% do contingente de pessoas pobres estimadas. As áreas rurais reúnem $26,3 \%$ e as áreas metropolitanas 22,6\% das famílias em situação de risco.

Vale chamar a atenção, também, para a última coluna da tabela 1 que apresenta os valores médios das rendas de cada um dos contingentes. A média da renda entre os pobres para o Brasil é de apenas R\$43,09 o que, em comparação com a linha de separação entre pobres e ricos, mostra que a pobreza no Brasil é profunda. Ou seja, a distância que separa a média da renda dos pobres da linha da pobreza ainda é bastante elevada. Mais elevada ainda é a distância entre essas linhas nas áreas rurais, aonde a média dos rendimentos está em apenas R\$ 39,11.

\section{Gráfico I: Pobres, segundo Regiões e Áreas de Resi- dência (exclusive Norte rural) - Brasil 200I}

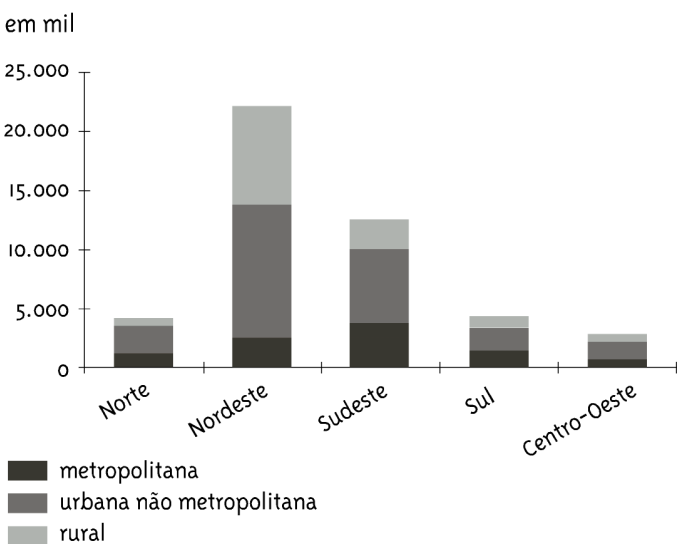

No Gráfico 1, apresentado anteriormente, observa-se que o Nordeste é a região que concentra o maior número de pobres. O Nordeste apresenta um contingente de pobres de 23 milhões, sendo que 8,2 milhões se encontram domiciliados nas áreas rurais e 8,2 milhões em áreas urbanas não metropolitanas. Essa região concentra também $68,5 \%$ dos pobres das áreas rurais do país.

Muito embora o Nordeste Rural seja apresentado como a área que apresenta a maior população de risco, a pobreza vem avançando muito nas áreas metropolitanas do Sul e Sudeste do Brasil. Numa comparação entre as diversas PNADs verifica-se que enquanto a pobreza no campo está estancada em níveis elevados, a pobreza nas grande cidades está crescendo em níveis alarmantes em função do desemprego e da falta de oportunidades econômicas. 0 estancamento da pobreza no campo se deve, em grande parte, a institucionalização do mecanismo de aposentadoria rural em caráter universal colocado em prática pela Constituição de 1988 (Delgado e Cardoso Jr, 200o). 0 Gráfico 2 ilustra esse movimento tomando o comparativo das PNADs de 1995 até 2001.

\section{Gráfico 2: Evolução da proporção das famílias com insegurança alimentar no Brasil 1995-200I}

\% famílias em relação

à população total

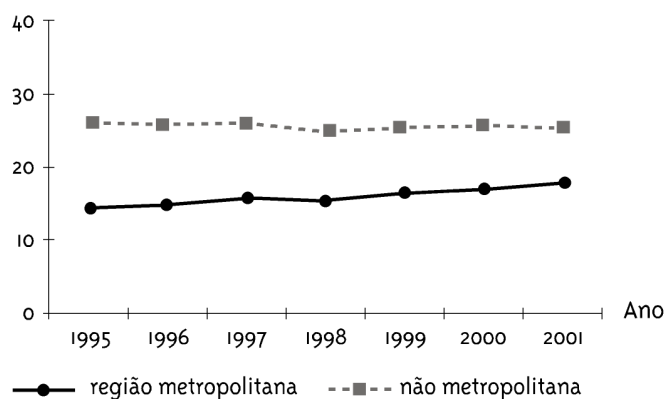

Fonte: Instituto Cidadania com base nas PNADs 


\section{Desenho de um Programa Integrado}

Como se observa, um programa que vise atender aos objetivos de segurança alimentar deve seguir diretrizes um pouco mais amplas que as atribuições exigidas para o combate à fome. Embora as áreas de incidência de fome endêmica sejam restritas a apenas algumas partes do Brasil, o tratamento a ser dado, do ponto de vista das políticas sociais, com o intuito de garantir a segurança alimentar, deve ser muito mais amplo. Costuma-se dizer popularmente que o nosso país possui problemas relativos à insegurança alimentar que são um tanto distintos daqueles encontrados na África Subsahariana onde o que falta é justamente o alimento. No Brasil, não temos problemas de oferta de alimentos, mas 46 milhões de indivíduos vivem em situação de risco, pois a sua renda é insuficiente para que eles possam se alimentar nas quantidades recomendadas $\mathrm{e}$ com a qualidade e regularidade necessária.

Um programa integrado de segurança alimentar deve atentar para os três elementos mencionados que dizem respeito ao acesso aos alimentos: quantidade suficiente, regularidade e qualidade. Dessa maneira, a questão não é apenas elevar a renda das pessoas pobres, mas, também, garantir que essa renda seja utilizada para o consumo de alimentos. É interessante destacar que é possível fazer com que o próprio consumo de alimentos seja uma alavanca para a inserção social produtiva dos setores excluídos. Fazendo com que as famílias pobres consumam alimentos produzidos por agricultores e pequenas agroindústrias locais é possível garantir que o aporte de renda proporcionado pelos programas sociais possa transbordar e gerar mais renda e emprego nas regiões deprimidas. Considerando que 47,3\% dos residentes das áreas rurais e $26,3 \%$ dos residentes das pequenas e médias cidades estão baixo da linha da pobreza (ver tabela 1) o impacto que pode ter uma política desse tipo é enorme. Essa dinâmica, conhecida pelos economistas como keynesiana, pode introduzir algo novo e diferente para o Brasil. Pela primeira vez, com o Fome Zero, poderemos ter no Brasil uma lógica em que a política social é capaz de alavancar o desenvolvimento econômico, e não o reverso, como tem sido ao longo da nossa história.

Esse ideal de um programa integrado de segurança alimentar foi apresentado à sociedade brasileira, em outubro de 2001, tendo sido organizado pelo Instituto Cidadania de S. Paulo, a partir do trabalho de quase uma centena de especialistas. Esse mesmo programa foi anunciado como prioridade pelo Presidente Luiz Inácio Lula da Silva, logo no seu primeiro discurso após ter sido eleito. Para tanto, o novo presidente criou um ministério específico para cuidar do tema, que passou a se articular com as demais áreas de governo com a finalidade de concretizar o PFZ.

Em resumo, o PFZ possui um conjunto de 25 políticas e 6 o programas apresentado em suas três dimensões: estruturais, específicas da alimentação e no âmbito das políticas locais. A seguir, vamos descrever cada uma dessas dimensões, exemplificando com as ações concretas que estão sendo propostas e implementadas.

As políticas estruturais mexem com as bases sociais e culturais das populações consideradas em situação de risco nutricional. Mediante o desenvolvimento de mecanismos que permitem o acesso a ativos de produção e educação, torna-se possível garantir a melhoria de renda, em bases permanentes, para os excluídos. Entre as políticas estruturais propostas e que estão sendo implementadas pelo PFZ estão: a) Políticas de geração de emprego e aumento de renda (microcrédito, incentivos a novos negócios, capacitação profissional, inclusão digital, primeiro emprego e outros); b) Intensificação da Reforma Agrária como forma de inclusão produtiva das famílias; c) Previdência Social Universal, trazendo de volta os trabalhadores informais; d) Intensificação e ampliação da Bolsa Escola para garantir que as novas gerações tenham um nível educacional mais elevado; e) Renda Mínima para as famílias em situação mais crítica e; f) Incentivo à agricultura familiar com a ampliação do crédito, compras governamentais, seguro-safra e outros mecanismos que possam garantir o escoamento da produção.

São denominadas políticas específicas aquelas que atuam diretamente sobre a questão alimentar. Entre as principais podemos mencionar: a) o cartão alimentação (transferência de renda condicionada para famílias carentes) que tem a propriedade de conseguir ligar os consumidores sem poder aquisitivo com os pequenos produtores de alimentos; b) ampliação e redirecionamento do Programa de Alimentação do Trabalhador - PAT. Estimativas mostram que, com a reformulação da forma de incentivo concedido às empresas 
seria possível incorporar mais de 40 milhões de trabalhadores ao programa, sem contar na possibilidade do PAT (a partir de modificações) atender, também, desempregados e aposentados; c) Combate à desnutrição materno-infantil, ampliando a atenção básica de saúde, além de garantia de fornecimento de produtos alimentares, como o leite, e de nutrientes básicos, como ferro e vitaminas, para as crianças inscritas nas redes públicas de serviços de saúde e de assistência social, visando universalizar os programas já existentes; d) Ampliação da Merenda Escolar, que já atende 38 milhões de crianças do ensino fundamental, para a pré-escola, abrangendo, também, o período de férias escolares e acrescentando outras refeições com melhor conteúdo nutricional e; e) Educação Alimentar com programas de informação para crianças em idade escolar e adultos, além do maior controle sobre a publicidade de alimentos f) Garantia de segurança e qualidade dos alimentos, através da ampliação do controle preventivo com a implementação de um sistema de informações e vigilância da segurança dos alimentos, a educação dos indivíduos envolvidos na cadeia produtiva, a promoção de estudos científicos e transferência de tecnologia e métodos para prevenir riscos e; g) Estoques de Segurança de Alimentos para regular a oferta e evitar as tradicionais oscilações nos preços dos alimentos. Ademais, para a formação de estoques, seria dada prioridade para a aquisição junto à pequena produção.

Finalmente, vamos fazer considerações no que tange às políticas locais, aquelas que estão ao alcance das organizações civis, prefeituras e consórcios de municípios. Entre essas políticas vale a pena mencionar apenas algumas, a saber: a) Restaurantes Populares para a população que vive e trabalha nas metrópoles cuja renda é baixa e onde são poucas as oportunidades de obter uma alimentação nutritiva e de qualidade; b) Banco de Alimentos e Colheita Urbana, aproveitando sobras que seriam desperdiçadas pela indústria de alimentos, restaurantes, cozinhas industriais e pelo varejo para atender a instituições e organizações de apoio a grupos carentes cadastradas previamente; c) Parceria com varejistas para a modernização do sistema de distribuição e escoamento da produção agrícola e agroindustrial local; d) apoio à agricultura familiar, através de abertura de linhas de crédito, assistência técnica e, inclusive, apoio à produção para o auto-consumo e; e) Agricultura urbana nas áreas urbanas não aproveitadas e terrenos baldios, para a plantação de hortaliças por parte de associações ou cooperativas de desempregados. Essas ações podem ser facilitadas pelos poderes público e civil local, através de cessão em comodato de áreas, crédito e abertura de sistemas de comercialização.

\section{Considerações finais}

Vimos nesse artigo que a abordagem da Segurança Alimentar e Nutricional permite ampliar o quadro estreito dos programas sociais tradicionais reconhecendo que a população em situação de risco pode ser maior do que aquela normalmente identificada. Foi mostrado, também, que as políticas de Segurança Alimentar e Nutricional devem trabalhar a necessidade de dar acesso aos alimentos para os grupos inseguros, atendendo as dimensões da quantidade, qualidade e regularidade no consumo de alimentos. Vale acrescentar, também, que o consumo de alimentos deve ser feito de forma digna, isto é, assegurando que as pessoas possam se alimentar com cidadania, sem que sejam tratadas com rações, pílulas e outras fórmulas muito utilizadas nos programas de combate à desnutrição.

O diagnóstico da segurança alimentar apontou que o problema brasileiro está assentado na absoluta falta de poder aquisitivo, por parte de quase um terço da população, para a manutenção da sua sobrevivência. Ao contrário de outros países pobres, o Brasil não tem problemas quanto à oferta de alimentos, esses estão disponíveis mas não são acessíveis à população de renda mais baixa. Por outro lado, estima-se que, se 46 milhões de pessoas em situação de risco fossem incorporadas imediatamente ao mercado de consumo, haveria uma demanda extra de $12 \%$ de arroz, $56 \%$ de feijão e $23 \%$ de leite (Guimarães, 2003) com uma incorporação de áreas produtivas da ordem de 3 milhões de hectares e o emprego extra de mais de 400 mil trabalhadores (Instituto Cidadania, 2001). Isso quer dizer que um programa integrado, como se propõe no Fome Zero, promoveria não apenas o lado do consumo, como o lado da produção, dando origem a um círculo virtuoso de crescimento.

Do ponto de vista social, as ações propostas pelo Fome Zero proporcionam o chamado "empoderamen- 
to" da comunidade. Ou seja, através do sistema de transferência de renda condicionada, em que as famílias recebem diretamente os recursos através de um cartão magnético e não há interferência direta do poder público local, as famílias e representantes da sociedade civil podem decidir, através de um comitê gestor, como devem se dar as contrapartidas por parte dos beneficiários dos programas. Pouco a pouco, com a freqüência em cursos de requalificação para desempregados, cursos de alfabetização, escola para as crianças, acompanhamento para gestantes e recém nascidos e outras ações essa famílias deixam a situação de risco, elevam a sua renda e adquirem auto-estima. Em adição a isso, as famílias passam a fazer parte de outros programas específicos para cada situação encontrada na comunidade.

\section{Referências Bibliográficas}

DELGADO, G. \& CARDOSO Jr., J. C. A universalização de direitos sociais no Brasil: a previdência rural nos anos 9o. Brasília: IPEA, 1990.

GUIMARÃES, O. Arroz, feijão e leite são insuficientes para tanta gente. Valor Econômico, São Paulo: 12 de maio de 2003 pag. F2, 2003.
HOFFMAN, R. Pobreza, insegurança alimentar e desnutrição no Brasil. Estudos Avançados, v.9 n. 24, 1995.

INSTITUTO CIDADANIA. Projeto Fome Zero - Uma Proposta de Política de Segurança Alimentar para o Brasil. São Paulo: Instituto Cidadania (117 pags), 2001.

LUSTOSA, T. Q. O. \& FIGUEIREDO, J. B. Pobreza no Brasil: métodos de análise e resultados. Pesquisa e Planejamento Econômico. Rio de Janeiro, v. 20, n.2, agosto de 1990.

MALUF, R. O Novo contexto internacional do abastecimento e da segurança alimentar In: Belik, W \& Maluf, R. Abastecimento e Segurança Alimentar. Campinas: Unicamp, 2000.

MONTEIRO, C. A. A dimensão da pobreza, da fome e da desnutrição no Brasil. Estudos Avançados, São Paulo, v.9, n.24, 1995.

PESSANHA, L. D. R. Pobreza, Segurança Alimentare Políticas Públicas: Contribuição ao Debate Brasileiro. (texto apresentado no Seminário "Sistemas Locais de Segurança Alimentar" realizado no Instituto de Economia da Unicamp em novembro de 2002. 1: Estimativa de Beneficiários de Programas de Combate à Fome, 2001. 